\title{
Significant role of microRNA-219-5p in diabetic retinopathy and its mechanism of action
}

\author{
JUNYING ZHAO $^{1}$, SHA GAO ${ }^{2}$, YANJI ZHU ${ }^{2}$ and $\mathrm{XI} \mathrm{SHEN}^{2}$ \\ ${ }^{1}$ Department of Ophthalmology, Dahua Hospital, Shanghai 200237; ${ }^{2}$ Department of Ophthalmology, \\ Ruijin Hospital, Shanghai Jiaotong University School of Medicine, Shanghai 200025, P.R. China
}

Received October 27, 2017; Accepted January 29, 2018

DOI: $10.3892 / \mathrm{mmr} .2018 .8988$

\begin{abstract}
Diabetic retinopathy (DR) is the leading cause of blindness and visual impairment. The role of microRNA (miRNA) in DR remains largely unknown. The present study aimed to investigate the role of miR-219-5p in the progression of DR. Human retinal pigment epithelial (RPE) cells were treated with a high concentration of glucose $(50 \mathrm{mM}$ D-glucose) for $24 \mathrm{~h}$ and the miR-219-5p level was detected using reverse transcription-quantitative polymerase chain reaction. The results revealed that miR-219-5p was significantly upregulated by high glucose (HG) treatment. To explore the role and mechanism of miR-219-5p in DR progression, miR-219-5p was downregulated in ARPE-19 cells. An MTT assay and flow cytometry were used to determine the level of viability and apoptosis of ARPE-19 cells, respectively. MicroRNA.org was used to predict the targets of miR-219-5p and the prediction was investigated using a dual-luciferase reporter assay. In addition, the level of associated proteins were measured using western blot analysis. It was observed that liver receptor homolog-1 (LRH-1) was a direct target of miR-219-5p. LRH-1 was significantly downregulated in ARPE-19 cells following HG treatment and negatively regulated by miR-219-5p in ARPE-19 cells. MiR-219-5p inhibitor significantly prevented ARPE-19 cell apoptosis induced by HG treatment and cell viability was markedly promoted. The results also suggested that the $\mathrm{LRH}-1 / \mathrm{Wnt} / \mathrm{\beta}-\mathrm{Catenin}$ signaling pathway was activated by miR-219-5p inhibition. In addition, it was revealed that LRH-1 inhibition eliminated the effects of miR-219-5p inhibitor on ARPE-19 cells. In conclusion, the results indicated that miR-219-5p was involved in the progression of DR through regulating human RPE cell apoptosis by modulation of the LRH-1/Wnt/ $\beta$-Catenin signaling pathway.
\end{abstract}

Correspondence to: Dr Xi Shen, Department of Ophthalmology, Ruijin Hospital, Shanghai Jiaotong University School of Medicine, 197 Ruijin 2nd Road, Shanghai 200025, P.R. China

E-mail: carl_shen2005@126.com

Key words: diabetic retinopathy, human retinal pigment epithelial cells, apoptosis, miR-219-5p, liver receptor homolog-1/Wnt/ $\beta$-catenin signaling pathway

\section{Introduction}

Diabetic retinopathy (DR), one of the most common complications of diabetes, is the leading cause of blindness and visual impairment in the working population (25-65 years old) in developing countries (1). As a kind of fundus lesions with specific changes, the pathology of DR is retinal micro-vascular dysfunction, and its clinical features are mainly manifestations of capillary periocular cell reduction, basement membrane thickening, abnormal proliferation of endothelial cells and angiogenesis, leading to macular edema, vitreous hemorrhage, retinal detachment and other serious injuries (2). At present, the treatment of DR is mainly through retinal photocoagulation and vitreous surgery, but the visual function of most patients has been already irreversibly damaged before the treatment. So far, DR is still lack of effective prevention and treatment. Therefore, seeking for new effective diagnosis and treatment methods has been a hot issue in the study of DR.

MicroRNAs (MiRNAs), a class of non-coding singlestranded small RNA, about 18-24 nucleotides in length, can transcriptionally or post-transcriptionally regulate the expression of the target genes by specific binding to the 3'-UTR of target mRNAs (3-5). MiRNAs play an important regulatory role in the process of visual function formation via involving in regulation of the physiological processes such as ocular development, neural differentiation, functional maintenance and apoptosis. Kovacs et al (6), have confirmed for the first time that the miRNAs expression profile has changed during DR. MiR-29 has been found to play important roles in the process of high glucose (HG) induced apoptosis in RPE cells, thus involved in DR progress (7). MiR-20b plays critical role in DR by targeting protein kinase B-3 (AKT3) (8). MiRNA-29a could down-regulate the expression of angiotensinogen (AGT), thereby repressing the development of DR (9). Moreover, miR-200b has been reported might alleviate DR development via the down-regulation of its target gene vascular endothelial growth factor A (VEGFA) (10).

MiR-219-5p, a tumor suppressor in a variety of cancers, may play an important role in regulating cell growth and apoptosis (11-14). So far, the expression and role of miR-219-5p in DR remain unclear. Therefore, the present study aimed to investigate the role of miR-219-5p in the development of DR, and to explore the underlying molecular mechanism. 


\section{Materials and methods}

Cell culture. The human retinal pigment epithelial (RPE) cell line ARPE-19 was obtained from the American Type Culture Collection (ATCC, Manassas, VA). Cells were cultured in DMEM/F-12 medium (Gibco; Thermo Fisher Scientific, Inc., Waltham, MA, USA) containing HG (25 mM D-glucose) or normal glucose (control, $5 \mathrm{mM}$ D-glucose) $(15,16), 10 \%$ fetal bovine serum (FBS; Gibco; Thermo Fisher Scientific, Inc.), 2 mM L-glutamine (Sigma-Aldrich; Merck KGaA, Darmstadt, Germany), $100 \mu \mathrm{g} / \mathrm{ml}$ streptomycin, and $100 \mathrm{units} / \mathrm{ml}$ penicillin (Sigma-Aldrich; Merck KGaA), and incubated at $37^{\circ} \mathrm{C}$ with $5 \% \mathrm{CO}_{2}$. The cells were passaged until reaching 80 90\% confluence.

Cell transfection. The day before cell transfection,ARPE-19 cells were seeded into a 6 -well plate at the concentration of $5 \times 10^{4}$ cells per well and cultured in a incubator at $37^{\circ} \mathrm{C}$ with $5 \% \mathrm{CO}_{2}$. Then the ARPE-19 cells were transfected with miR-219-5p inhibitor, its negative control, or miR-219-5p inhibitor+LRH-1-siRNA with $30 \mu 1$ Lipofectamine 2000 (Invitrogen; Thermo Fisher Scientific, Inc.) according to the manufacturer's protocol. Cells without any treatment were recognized as the control group. These cells were initially transfected for $6 \mathrm{~h}$, then the culture medium was replaced with DMEM/F-12 medium containing $50 \mathrm{mM} \mathrm{HG}$ (7). After incubation for $24 \mathrm{~h}$, the cells were subjected to following experiments.

Cell viability assay. Twenty four hours after treatment, cell viability assay was used to measure the cell viability. Briefly, ARPE-19 cells were trypsinized, re-suspended, and then reseeded into 96 -well plates and incubated at $37^{\circ} \mathrm{C}$ for 24,48 and $72 \mathrm{~h}$ respectively. Subsequently, $20 \mathrm{mg} / \mathrm{ml}$ MTT solution (Sigma-Aldrich; Merck KGaA) was added into each well and then incubated for another $4 \mathrm{~h}$. At the end of the experiment, the optical density (OD) value at $570 \mathrm{~nm}$ was detected by using a SynergyTM 2 Multi-function Microplate Reader (Bio-Tek Instruments, Inc., Winooski, VT, USA). Tests were repeated at least for three times.

Cell apoptosis assay. To analyze cell apoptosis, cell apoptosis assay was performed using flow cytometry (BD Biosciences, Franklin Lakes, NJ, USA). $24 \mathrm{~h}$ after treatment, ARPE-19 cells were stained with annexin V-FITC and propidium iodide (PI) (CST Biological Reagents Co., Ltd., Shanghai, China) in line with the manufacturer's instructions. Finally, we used flow cytometry to analyze cell apoptosis. Tests were repeated at least for three times.

RNA extraction and quantitative RT-PCR. Total RNA was extracted from ARPE-19 cells by using TRIZOL reagent (Invitrogen; Thermo Fisher Scientific, Inc.) following the manufacturer's protocol. The total RNA was reversely transcripted into cDNA using a PrimeScript reverse transcription reagent kit (Takara Biotechnology Co., Ltd., Dalian, China). Subsequently, TaqMan Universal PCR Master Mix kit (Thermo Fisher Scientific, Inc.) was performed to analyze the synthesized cDNAs. The amplification conditions were as follows: $95^{\circ} \mathrm{C}$ for $10 \mathrm{~min}$, followed by 40 cycles of $95^{\circ} \mathrm{C}$ for $10 \mathrm{sec}$ and $57^{\circ} \mathrm{C}$ for $60 \mathrm{sec}$. All primer sequences were

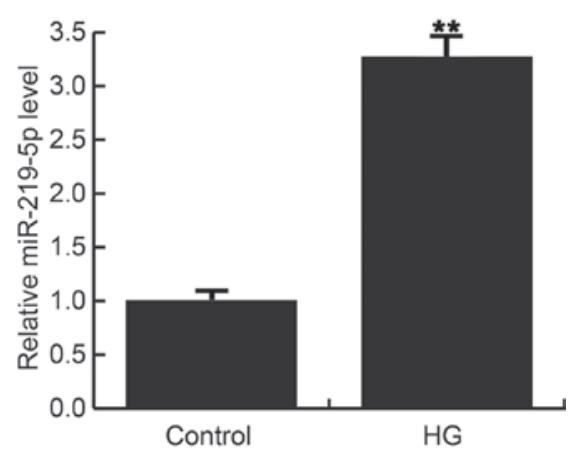

Figure 1. Effect of HG on miR-219-5p expression in ARPE-19 cells. Reverse transcription-quantitative polymerase chain reaction analysis of miR-219-5p expression in ARPE-19 cells following treatment with $0 \mathrm{mM}$ D-glucose or HG. HG, high glucose. ${ }^{* *} \mathrm{P}<0.01$ vs. Control. HG, $50 \mathrm{mM}$ D-glucose.

obtained from Genscript (Nanjing, China), and the relative gene expression was analyzed by using the $2^{-\Delta \Delta C q}$ method (17).

Western blot analysis. After treatment for $24 \mathrm{~h}$, ARPE-19 cells were harvested by microcentrifugation. Total cell protein was extracted using the lysis buffer (Promega Corporation, Madison, WI, USA). Equal amount of the samples were separated by SDS-polyacrylamide gel electrophoresis and then transferred onto an enhanced nitrocellulose membrane. Blots were blocked with 5\% skim milk at room temperature for $2 \mathrm{~h}$, incubated with the primary antibody against LRH-1 (cat no. 12800), $\beta$-catenin (cat no. 8480), Cyclin D1 (cat no. 2978), c-Myc (cat no. 13978) (all dilution: 1:1,000) and $\beta$-actin (cat no. 4970; dilution: 1:5,000) (dilution: 1:1,000; all from Cell Signaling Technology, Danvers, MA, USA) at $4^{\circ} \mathrm{C}$ overnight, and then incubated with a secondary antibody at room temperature for $2 \mathrm{~h}$. At the end of the test, blots were observed by using the enhanced chemiluminescence detection system (Super Signal West Dura Extended Duration Substrate; Pierce; Thermo Fisher Scientific, Inc.).

Dual-luciferase reporter assay. We used bioinformatics software (http://www.microrna.Org/microrna/home.do) to predict the promising targets of miR-219-5p, and we found that LRH-1 was potentially targeted by miR-219-5p. In order to confirm our prediction, dual-luciferase reporter assay was applied. In brief, the 3'UTR of LRH-1 gene, which includes the miR-219-5p binding domain, was sub-cloned into the XhoI and NotI sites of a psiCHECK2 luciferase vector (Promega Corporation) (LRH-1 WT). To point-mutate the miR-219-5p binding domain on the 3'UTR of LRH-1, a QuikChange Site-Directed Mutagenesis kit (Agilent Technologies, Inc., Santa Clara, CA, USA) was performed according to the manufacturer's instructions. Then the mutated LRH-1 3'UTR was sub-cloned into psiCHECK2 luciferase vector (LRH-1 MUT). ARPE-19 cells were co-transfected with LRH-1 WT or LRH-1 MUT and miR-219-5p mimic or miR-control (control of miR-219-5p mimic). $48 \mathrm{~h}$ later, the dual-luciferase reporter assay system (Promega Corporation) was carried out to determine the luciferase activity.

Statistical analysis. SPSS v16.0 statistical software (SPSS, Inc., Chicago, IL, United States) was applied for all statistical 
$\mathbf{A}$

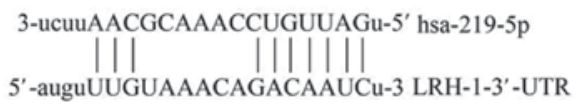

C

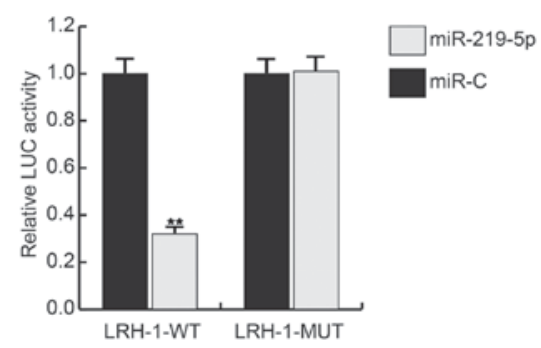

$\mathbf{E}$

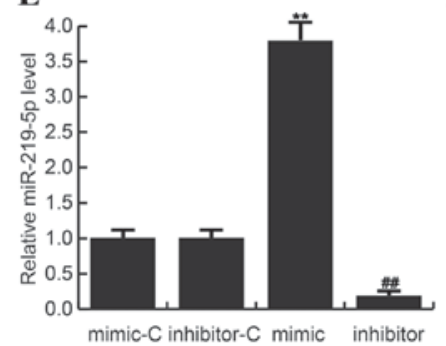

B

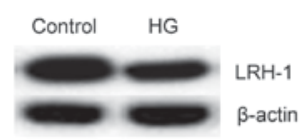

D

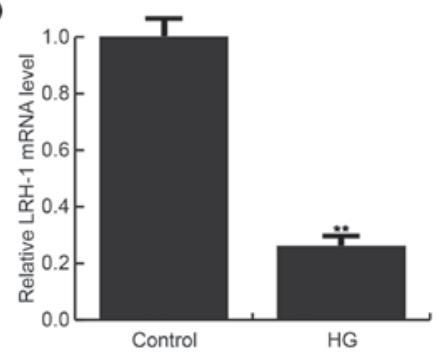

G

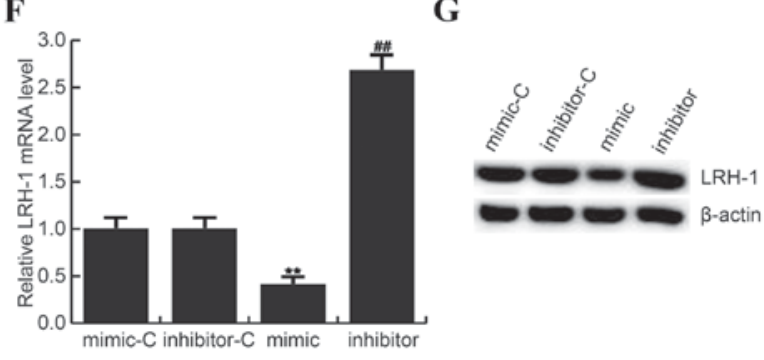

Figure 2. LRH-1 is a direct target of miR-219-5p. (A) Bioinformatics software (http://www.microrna.Org/microrna/home.do) was carried out to predict the interaction between miR-219-5p and LRH-1 3'UTR. (B) Luciferase activity was detected by Dual luciferase assay. Here, (C) protein level of LRH-1 in ARPE-19 cells after treatment with $0 \mathrm{mM}$ D-glucose (Control) or $50 \mathrm{mM}$ D-glucose. D: mRNA level of LRH-1 in ARPE-19 cells after treatment with 0 mM D-glucose (Control) or 50 mM D-glucose. (D) Effect of miR-219-5p inhibitor on LRH-1 mRNA expression in ARPE-19 cells. Relative expression of (E) miR-219-5p and (F) LRH-1 in different groups. (G) Effect of miR-219-5p inhibitor on LRH-1 protein expression in in ARPE-19 cells. ${ }^{* *} \mathrm{P}<0.01$ vs Control; ${ }^{\# /} \mathrm{P}<0.01$ vs. Control. Data are displayed as mean \pm standard deviation. UTR, untranslated region; HG, high glucose, cells treated with $50 \mathrm{mM}$ D-glucose; inhibitor, cells transfected with miR-219-5p inhibitors and treated with 50 mM D-glucose; inhibitor+si-LRH-1, cells co-transfected with miR-219-5p inhibitors and LRH-1-siRNA, and treated with $50 \mathrm{mM}$ D-glucose. miR, microRNA; LRH, liver receptor homolog; MUT, LRH-1 3' UTR with a mutation in the miR-219-5p binding site; WT, wild type; LUC, luciferase.

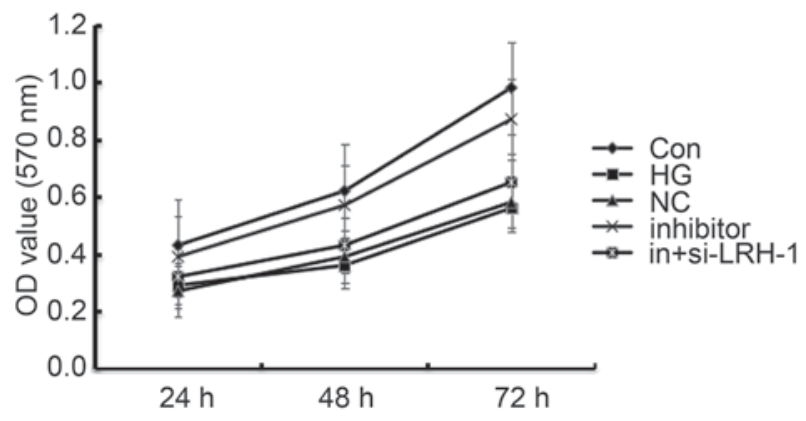

Figure 3. Effects of miR-219-5p inhibitor on ARPE-19 cell viability. ARPE-19 cell viability was measured by an MTT assay 24,48 and $72 \mathrm{~h}$ post treatment. Data are displayed as the mean \pm standard deviation. Con, control group; $\mathrm{HG}$, high glucose, cells treated with $50 \mathrm{mM}$ D-glucose; NC, negative control, cells transfected with the negative control of miR-219-5p inhibitor and treated with $50 \mathrm{mM}$ D-glucose; inhibitor, cells transfected with miR-219-5p inhibitors and treated with $50 \mathrm{mM} \mathrm{D-glucose}$; in+si-LRH-1, cells co-transfected with miR-219-5p inhibitors and liver receptor homolog-1-siRNA, and treated with $50 \mathrm{mM}$ D-glucose; OD, optical density.

analyses. Data were presented as the mean $\pm \mathrm{SD}$. Comparison between two groups were made by Student's t-test, between multiple groups by one-way ANOVA followed by Tukey's test. $\mathrm{P}<0.05$ was considered to indicate a statistically significant difference.

\section{Results}

MiR-219-5p was up-regulated in HG treated ARPE-19 cells. In current study, we firstly treated ARPE-19 cells with $50 \mathrm{mM}$ D-glucose or $0 \mathrm{mM}$ D-glucose (control). Consistent with a previous study, significant apoptosis in ARPE-19 cells was induced after treatment with $50 \mathrm{mM}$ D-glucose, as compared to the control group with $0 \mathrm{mM}$ D-glucose. $24 \mathrm{~h}$ after treatment, miR-219-5p was detected using qRT-PCR, and the results indicated that compared with the control cells, miR-219-5p expression was significantly up-regulated in HG treated ARPE-19 cells (Fig. 1).

MiR-219-5p directly targets LRH-1. Bioinformatics software (http://www.microrna.Org/microrna/home.do) was performed to predict the targets of miR-219-5p. About 4000 targets were found to be potentially targeted by miR-219-5p, including LRH-1 (Fig. 2A). LRH-1 has been revealed to play an important role in the regulation of cell proliferation and apoptosis via controlling the Wnt/ $\beta$-catenin signaling pathways $(12,18)$. However, whether LRH-1 functions its role in DR is still unclear. Therefore, we choose LRH-1 to make further investigation. And the results of dual-luciferase reporter assay indicated that miR-219-5p directly targets LRH-1 at 3'UTR domain (Fig. 2B). And the lower expression 


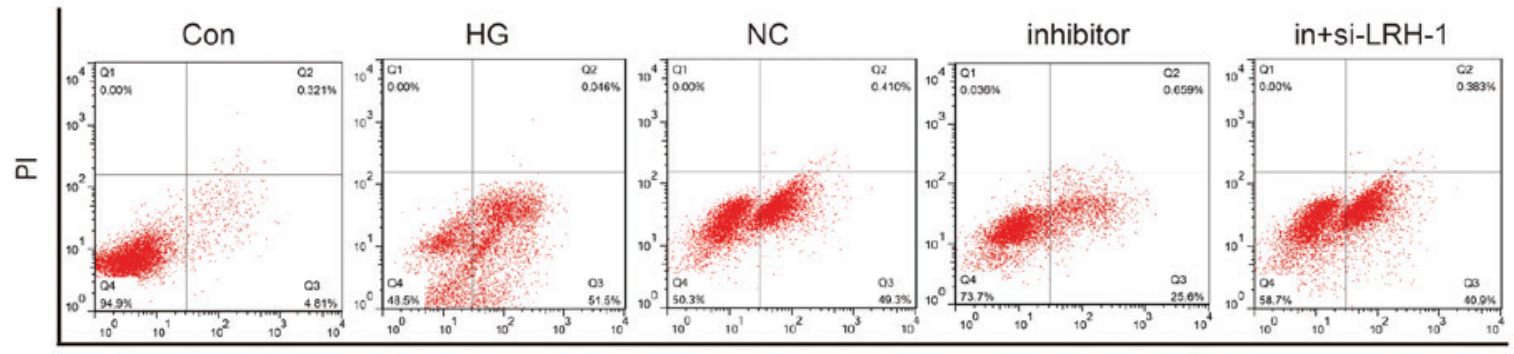

Annexin V-FITC

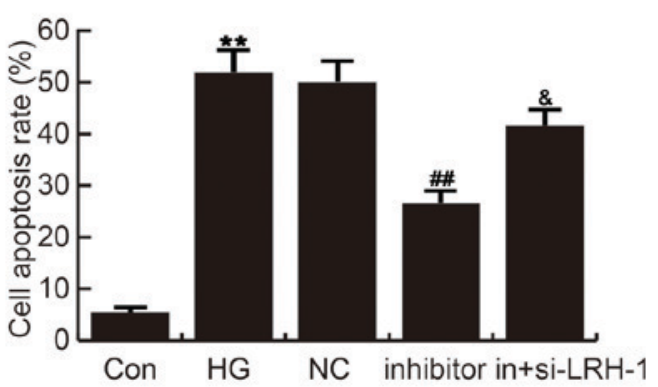

Figure 4. Effects of miR-219-5p inhibitor on ARPE-19 cell apoptosis. ARPE-19 cell apoptosis was detected by flow cytometry. And cell apoptosis rate was detected. Data are displayed as the mean \pm standard deviation. ${ }^{* *} \mathrm{P}<0.01$ vs. Con; ${ }^{\# \#} \mathrm{P}<0.01$ vs. HG; ${ }^{\circ} \mathrm{P}<0.05$ vs. inhibitor. Con, control group; HG, high glucose, cells treated with $50 \mathrm{mM} \mathrm{D}$-glucose; NC, negative control, cells transfected with the negative control of miR-219-5p inhibitor and treated with $50 \mathrm{mM}$ D-glucose; inhibitor, cells transfected with miR-219-5p inhibitors and treated with 50 mM D-glucose; in+si-LRH-1, cells co-transfected with miR-219-5p inhibitors and liver receptor homolog-1-siRNA, and treated with $50 \mathrm{mM}$ D-glucose.

A

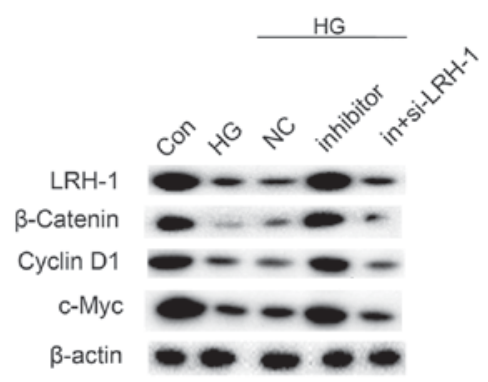

C

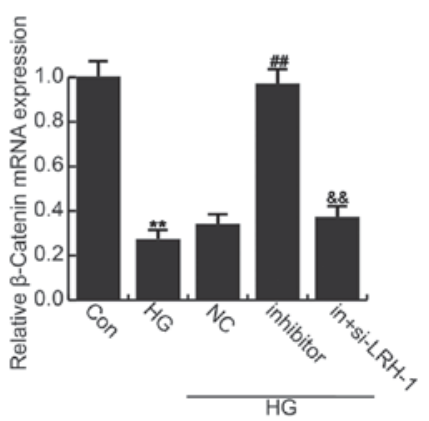

D

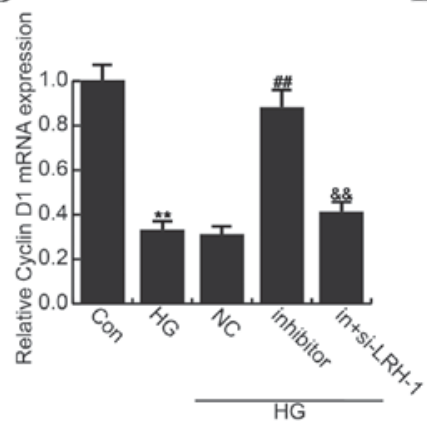

B

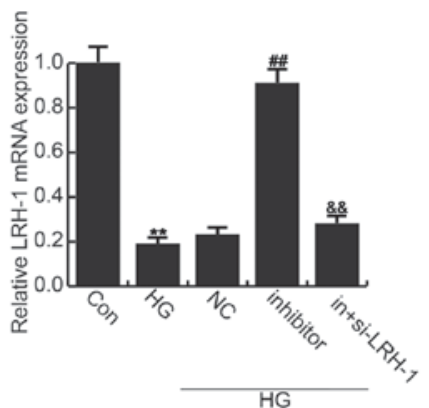

$\mathbf{E}$

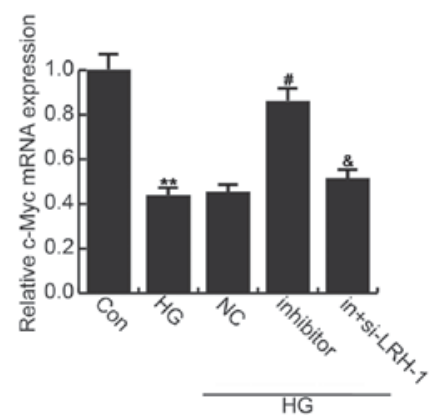

Figure 5. Effects of miR-219-5p inhibitor on Wnt/ $\beta$-Catenin signaling pathway. (A) At $24 \mathrm{~h}$ post treatment, the protein expression of LRH-1, $\beta$-Catenin, Cyclin D1 and c-Myc was determined by western blot analysis. The mRNA level of (B) LRH-1, (C) $\beta$-Catenin, (D) Cyclin D1 and (E) c-Myc was determined by reverse transcription-quantitative polymerase chain reaction. Data are displayed as the mean \pm standard deviation. ${ }^{* *} \mathrm{P}<0.01$ vs. Con; ${ }^{~} \mathrm{P}<0.05$ and ${ }^{\# \# /} \mathrm{P}<0.01$ vs. HG; ${ }^{\&} \mathrm{P}<0.05$ and ${ }^{\&} \mathrm{P}<0.01$ vs. inhibitor. Con, control group; HG, high glucose, cells treated with $50 \mathrm{mM}$ D-glucose; NC, negative control, cells transfected with the negative control of miR-219-5p inhibitor and treated with $50 \mathrm{mM}$ D-glucose; inhibitor, cells transfected with miR-219-5p inhibitors and treated with $50 \mathrm{mM}$ D-glucose; in+si-LRH-1, cells co-transfected with miR-219-5p inhibitors and LRH-1-siRNA, and treated with 50 mM D-glucose; LRH, liver receptor homolog.

of LRH-1 in HG treated ARPE-19 cells was observed in the current study (Fig. 2C and D).

Then we determined whether miR-219-5p regulates LRH-1 expression in ARPE-19 cells, miR-219-5p mimic, mimic control, miR-219-5p inhibitor or inhibitor control was transfected into ARPE-19 cells, and the transfection efficiency was assessed by qRT-PCR (Fig. 2E). The findings suggested that miR-219-5p mimic significantly decreased both 
mRNA (Fig. 2F) and protein (Fig. 2G) level of LRH-1 (55 kD) in ARPE-19 cells, while miR-219-5p inhibitor presented the opposite effects.

MiR-219-5p inhibitor promoted ARPE-19 cell viability. Influence of miR-219-5p inhibitor on ARPE-19 cell activity was detected using MTT assay. Compared with the control group, the viability of ARPE-19 cell seriously reduced in the HG group, and the declined cell viability was rescued by miR-219-5p inhibitor. In addition, LRH-1-siRNA eliminated the enhanced cell viability caused by miR-219-5p inhibitor (Fig. 3).

MiR-219-5p inhibitor repressed HG induced ARPE-19 cell apoptosis. The effects of miR-219-5p inhibitor on ARPE-19 cell apoptosis was analyzed by cell apoptosis assay with FCM. Compared with the control group, ARPE-19 cell apoptosis was significantly induced in HG group, which was repressed by miR-219-5p inhibitor administration. These changes caused by miR-219-5p inhibitor were eliminated by LRH-1-siRNA (Fig. 4).

MiR-219-5p inhibitor rescued the LRH-1/Wnt/ $\beta$-Catenin inhibition caused by $H G$. Finally, in order to explore the underlying molecular mechanism of the role miR-219-5p played in DR process, LRH-1/Wnt/ $\beta$-Catenin pathway was analyzed, and western blotting and qRT-PCR was performed respectively. As shown in Fig. 5, compared with the control group, the level of LRH-1 (55 kD), $\beta$-Catenin (92 kD), Cyclin D1 (36 kD) and c-Myc (62 kD) significantly reduced in HG treated ARPE-19 cells, and miR-219-5p inhibitor markedly enhanced LRH-1, $\beta$-Catenin, Cyclin D1 and c-Myc expression when compared to the HG group. LRH-1 gene silencing eliminated the effects caused by miR-219-5p inhibitor (Fig. 5).

\section{Discussion}

Irreversible damage of the blood-retina barrier (BRB) may caused by hyperglycemia or HG, resulting in loss of vision or blindness, during DR (19). Hyperglycemia or HG induced apoptosis in RPE cells, the essential elements of BRB, is a characteristic process in DR (20). Increasing evidences have suggested a regulatory function and the potential influences of microRNAs in DR treatment. MiR-219-5p has been reported as a tumor suppressor in a large number of cancers via the regulation of cell migration, invasion, proliferation and apoptosis $(11-14,21)$. However, the regulation of cell apoptosis by miR-219-5p on human RPE cells remains unclear. The present study aimed to investigate the expression of miR-219-5p in human RPE cells, and to further explore its role in regulating human RPE cell apoptosis under HG conditions.

According a precious study, $50 \mathrm{mM}$ D-glucose could significantly induced human RPE cell apoptosis (7). Firstly, we examined the level of miR-219-5p in human RPE cells after treatment with $50 \mathrm{mM}$ D-glucose for $24 \mathrm{~h}$, and the findings suggested that miR-219-5p was significantly up-regulated, indicating miR-219-5p may be involved in the process of DR. Then we found that about 4000 targets may be targeted by miR-219-5p, including LRH-1. LRH-1 (liver receptor homologue-1), also called NR5A2, is a member of the nuclear receptor subfamily which is involved in various biological processes, including differentiation, steroid synthesis, and bile-acid homeostasis, etc (22-24). Recently, a large number of studies have revealed that LRH-1 plays a key role in regulating cell growth, including apoptosis $(12,18,25-28)$. Due to its unclear role in DR, LRH-1 was further explored in the present study. Our results indicated that LRH-1 was a direct target of miR-219-5p, and LRH-1 was lower expressed in HG treated human RPE cells compared to the control cells. Moreover, our findings showed that LRH-1 was negatively regulated by miR-219-5p in human RPE cells. These findings suggested that miR-219-5p may participate in the development of DR by targeting LRH-1.

To study the role and molecular mechanism of miR-219-5p in DR, we determined the effect of miR-219-5p inhibitor on human RPE cell viability and cell apoptosis, and we found that miR-219-5p inhibitor notably promoted human RPE cell viability which was inhibited by HG treatment, and repressed HG induced human RPE cell apoptosis. LRH-1/Wnt/ $\beta$-Catenin pathway was inhibited in human RPE cells after HG treatment, and this inhibition was rescued by miR-219-5p inhibition. In addition, we revealed that the effects of miR-219-5p inhibitor on human RPE cells could be eliminated by LRH-1-siRNA under HG condition.

In summary, our study demonstrated that $\mathrm{HG}$ resulted in the up-regulation of miR-219-5p expression in human RPE cells. MiR-219-5p down-regulation promoted human RPE cell viability and inhibited cell apoptosis through regulating LRH-1/Wnt/ $\beta$-Catenin pathway by targeting LRH-1. MiR-219-5p/LRH-1 may be promising therapeutic targets for DR.

\section{Competing interests}

The authors declare that they have no competing interests.

\section{References}

1. Ding J and Wong TY: Current epidemiology of diabetic retinopathy and diabetic macular edema. Curr Diab Rep 12: 346-354, 2012.

2. Yau JW, Rogers SL, Kawasaki R, Lamoureux EL, Kowalski JW, Bek T, Chen SJ, Dekker JM, Fletcher A, Grauslund J, et al: Global prevalence and major risk facers of diabetic retinopathy. Diabetes Care 35: 556-564, 2012.

3. Kim VN, Han J and Siomi MC: Biogenesis of small RNAs in animals. Nat Rev Mol Cell Biol 10: 126-139, 2009.

4. Bartel DP: MicroRNAs: Target recognition and regulatory functions. Cell 136: 215-233, 2009.

5. Valencia-Sanchez MA, Liu J, Hannon GJ and Parker R: Control of translation and mRNA degradation by miRNAs and siRNAs. Genes Dev 20: 515-524, 2006.

6. Kovacs B, Lumayag S, Cowan C and Xu S: MicroRNAs in early diabetic retinopathy in streptozotocin-induced diabetic rats Invest Ophthalmol Vis Sci 52: 4402-4409, 2011.

7. Lin X, Zhou X, Liu D, Yun L, Zhang L, Chen X, Chai Q and Li L: MicroRNA-29 regulates high-glucose-induced apoptosis in human retinal pigment epithelial cells through PTEN. In Vitro Cell Dev Biol Anim 52: 419-426, 2016.

8. Qin B, Liu J, Liu S, Li B and Ren J: MiR-20b targets AKT3 and modulates vascular endothelial growth factor-mediated changes in diabetic retinopathy. Acta Biochim Biophys Sin (Shanghai) 48: 732-740, 2016.

9. Zhang LQ, Cui H, Wang L, Fang X and Su S: Role of microRNA-29a in the development of diabetic retinopathy by targeting AGT gene in a rat model. Exp Mol Pathol 102: 296-302, 2017.

10. Li EH, Huang QZ, Li GC, Xiang ZY and Zhang X: Effects of miRNA-200b on the development of diabetic retinopathy by targeting VEGFA gene. Biosci Rep 37: pii: BSR20160572, 2017. 
11. Wang Q, Zhu L, Jiang Y, Xu J, Wang F and He Z: miR-219-5p suppresses the proliferation and invasion of colorectal cancer cells by targeting calcyphosin. Oncol Lett 13: 1319-1324, 2017.

12. Li C, Dong J, Han Z and Zhang K: MicroRNA-219-5p represses the proliferation, migration, and invasion of gastric cancer cells by targeting the LRH-1/Wnt/ $\beta$-catenin signaling pathway. Oncol Res 25: 617-627, 2017.

13. Huang C, Cai Z, Huang M, Mao C, Zhang Q, Lin Y, Zhang X, Tang B, Chen Y, Wang X, et al: miR-219-5p modulates cell growth of papillary thyroid carcinoma by targeting estrogen receptor $\alpha$. J Clin Endocrinol Metab 100: E204-E213, 2015.

14. Huang N, Lin J, Ruan J, Su N, Qing R, Liu F, He B, Lv C, Zheng D and Luo R: MiR-219-5p inhibits hepatocellular carcinoma cell proliferation by targeting glypican-3. FEBS Lett 586: 884-891, 2012.

15. Ruiz MA, Feng B and Chakrabarti S: Polycomb repressive complex 2 regulates MiR-200b in retinal endothelial cells: Potential relevance in diabetic retinopathy. PLoS One 10 e0123987, 2015.

16. Zhao S, Li T, Li J, Lu Q, Han C, Wang N, Qiu Q, Cao H, Xu X, Chen $\mathrm{H}$ and Zheng $\mathrm{Z}$ : miR-23b 3p induces the cellular metabolic memory of high glucose in diabetic retinopathy through a SIRT1-dependent signalling pathway. Diabetologia 59: 644-654, 2016.

17. Livak KJ and Schmittgen TD: Analysis of relative gene expression data using real-time quantitative PCR and the 2(-Delta Delta C(T)) method. Methods 25: 402-408, 2001.

18. Zhai G, Song J, Shu T, Yan J, Jin X, He J and Yin Z: LRH-1 senses signaling from phosphatidylcholine to regulate the expansion growth of digestive organs via synergy with Wnt/ $\beta$-catenin signaling in zebrafish. J Genet Genomics 44: 307-317, 2017.

19. Ahsan H: Diabetic retinopathy-biomolecules and multiple pathophysiology. Diabetes Metab Syndr 9: 51-54, 2015.
20. Simó R, Villarroel M, Corraliza L, Hernández C and Garcia-Ramírez M: The retinal pigment epithelium: Something more than a constituent of the blood-retinal barrier-implications for the pathogenesis of diabetic retinopathy. J Biomed Biotechnol 2010: 190724, 2010.

21. Cheng J, Deng R, Zhang P, Wu C, Wu K, Shi L, Liu X, Bai J, Deng M, Shuai X, et al: miR-219-5p plays a tumor suppressive role in colon cancer by targeting oncogene Sall4. Oncol Rep 34: 1923-1932, 2015.

22. Sablin EP, Blind RD, Uthayaruban R, Chiu HJ, Deacon AM, Das D, Ingraham HA and Fletterick RJ: Structure of liver receptor homolog-1 (NR5A2) with PIP3 hormone bound in the ligand binding pocket. J Struct Biol 192: 342-348, 2015.

23. Fayard E, Auwerx J and Schoonjans K: LRH-1: An orphan nuclear receptor involved in development, metabolism and steroidogenesis. Trends Cell Biol 14: 250-260, 2004.

24. Stein S and Schoonjans K: Molecular basis for the regulation of the nuclear receptor LRH-1. Curr Opin Cell Biol 33: 26-34, 2015.

25. Zhang Q, Zhao S, Pang X and Chi B: MicroRNA-381 suppresses cell growth and invasion by targeting the liver receptor homolog-1 in hepatocellular carcinoma. Oncol Rep 35: 1831-1840, 2016.

26. Jiang W, Tian $Y$, Jiang $S$, Liu S, Zhao $X$ and Tian D: MicroRNA-376c suppresses non-small-cell lung cancer cell growth and invasion by targeting LRH-1-mediated Wnt signaling pathway. Biochem Biophys Res Commun 473: 980-986, 2016.

27. Baquié M, St-Onge L, Kerr-Conte J, Cobo-Vuilleumier N, Lorenzo PI, Jimenez Moreno CM, Cederroth CR, Nef S, Borot S, Bosco D, et al: The liver receptor homolog-1 (LRH-1) is expressed in human islets and protects $\{$ beta\}-cells against stress-induced apoptosis. Hum Mol Genet 20: 2823-2833, 2011.

28. Wang S, Lan F, Huang L, Dong L, Zhu Z, Li Z, Xie Y and Fu J: Suppression of hLRH-1 mediated by a DNA vector-based RNA interference results in cell cycle arrest and induction of apoptosis in hepatocellular carcinoma cell BEL-7402. Biochem Biophys Res Commun 333: 917-924, 2005. 